\title{
High-Yield Laccase-Producing Strains Constructed by Protoplast Fusion Between Bacterium and Fungus
}

\author{
Lihong Zhao*, Wenli Yin and Lele Wang \\ Civil \& Architectural Engineering College, Liaoning University of Technology, Jinzhou, China
}

\begin{abstract}
This study is based on the construction of high-yield laccase-producing fusant achieved by inter-kingdom protoplast fusion between Pleurotus ostreatus and Escherichia coli. The optimized protoplasts formation and regeneration conditions were demonstrated with the presence of $1.5 \%$ cellulase $+1.0 \%$ snailase and $0.6 \mathrm{M}$ mannitol at $30^{\circ} \mathrm{C}$ for $3 \mathrm{~h}$. The fusants were screened for different characteristics between two parental strains and further identified by laccase activity, offering one of the genetically stable fusants, Strain F. The fusant F produced the highest yield of laccase, being about $22 \%$ higher than that of the parental strain. The results suggest that the protoplast fusion technique can be considered as a promising technique for the control of environmental pollution.
\end{abstract}

Keywords: Escherichia coli, Laccase, Pleurotus ostreatus, Protoplast fusion, White rot fungi.

\section{INTRODUCTION}

Laccase, representing the largest subgroup of blue multicopper oxidases (MCO), uses distinctive redox ability of copper ions to catalyze the oxidation of a wide range of aromatic substrates concomitantly with the reduction of molecular oxygen in water [1]. Laccase has also been found in various basidiomycetous and ascomycetous fungi and, thus farfungal laccase has accounted for the most important group of MCOs with respect to the number and extent of characterization. Especially white-rot fungi produce laccase which efficiently degrades lignin. Pleurotus ostreatus is one of the unusual white rot fungi that it is able to mineralize the compound of native lignin. Moreover, it can also degrade almost all hazardous organic pollutants. Its potential would be enhanced, if genetic methods for producing strains with superior capacities were available. Therefore, laccase has important application value in the degradation of lignin, biological pulping, biobleaching and catalytic synthesis, biological elimination of toxic compounds [2-4], and has become a hotspot in the research of enzyme engineering and environmental protection. But due to its low yield and slow growth of white rot fungi, there is a problem to be solved for practical application of laccase in the industry.

Protoplast fusion has been an established technique for more than 30 years, but this traditional technique is still a powerful tool for the improvement of various microorganisms. Protoplast fusion has indicated broad applicability among microorganisms not only between intraspecies but also interspecies microbes and even between microbes from different kingdoms [5-9].

The aim of this work was to generate high-yield laccaseproduction and fast growth strains from Pleurotus ostreatus

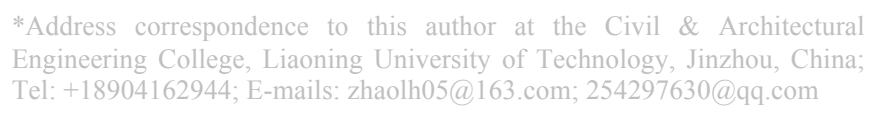

*Address correspondence to this author at the Civil \& Architectural Tel: +18904162944; E-mails: zhaolh05@163.com; 254297630@qq.com

1874-0707/15 and Escherichia coli through the combination of protoplast fusion technique.

\section{MATERIAL AND METHODS}

\subsection{Strains and Culture Medium}

The fungal strain $P$. ostreatus was obtained from the microbiology laboratory, Civil and Architectural Engineering College, Liaoning University of Technology, Jinzhou, China. $E$. coli was obtained from the China Center of Industrial Culture Collection. P. ostreatus was maintained on potatodextrose-agar (PDA) medium. E. coli was cultivated from Luria-Bertani (LB) medium (tryptone $10 \mathrm{~g} / \mathrm{l}, \mathrm{NaCl} 10 \mathrm{~g} / \mathrm{l}$, yeast extract $5 \mathrm{~g} / \mathrm{l}, \mathrm{pH} 7.6)$. Mycelia were cultured in PDA liquid medium under different conditions at $30^{\circ} \mathrm{C}$ for 6-7 days for $P$. ostreatus and E. coli was cultured in LB liquid medium under different conditions at $37^{\circ} \mathrm{C}$ for $12-13$ hours for $E$. coli prior to protoplast isolation.

\subsection{Formation of Protoplasts}

Mycelia of $P$. ostreatus at different incubation time were harvested by suction filtration, carefullyto prevent the mycelium from drying extensively, and washed with corresponding osmotic stabilizer $\left(\mathrm{MgSO}_{4}, \mathrm{KCl}, \mathrm{NaCl}\right.$, mannitol). Cells $(0.1$ to $1.0 \mathrm{~g})$ in $1 \mathrm{ml}$ of stabilizer were treated with the cell-wall-degrading enzymes at $30^{\circ} \mathrm{C}$ with shaking for $3 \mathrm{~h}[10]$. The cell-wall-degrading enzymes such as snailase, lywallzyme and cellulase were tested in different combinations, so as to get the optimum digestion conditions. Remaining fragments were removed by filtration (coarse fritted glass funnel), and the protoplasts were sedimented by centrifugation at 4,000 rpm for $10 \mathrm{~min}$ and resuspended in the stabilizer as indicated. The number of protoplasts in suspension was determined with a hemacytometer.

E. coli strain was grown in LB medium to an optical density at $600 \mathrm{~nm}$ of 0.9 to 1.0 at $37^{\circ} \mathrm{C}$. The cells were 
harvested by centrifugation at $4^{\circ} \mathrm{C}$ at $10,000 \mathrm{rpm}$ for $5 \mathrm{~min}$. The bacteria were washed twice at $23^{\circ} \mathrm{C}$ with $10 \mathrm{mM}$ tris(hydroxymethyl)aminomethane (Tris) buffer ( $\mathrm{pH} 8.0)$. The pellet was suspended by pipetting. Suspension in $45 \mathrm{ml}$ of 0.1 $\mathrm{M}$ Tris, with $\mathrm{pH} 8.0$, containing $20 \%$ (w/w) sucrose was maintained at $37^{\circ} \mathrm{C}$ directly in the centrifuge tube. Cells were then transferred to a small flask, and the temperature was adjusted to $37^{\circ} \mathrm{C}$. Within $1 \mathrm{~min}, 2.25 \mathrm{ml}$ of a $2 \mathrm{mg} / \mathrm{ml}$ solution of lysozyme in doubledistilled water was added for a final concentration of $100 \mu \mathrm{g}$ of lysozyme per ml. During the addition of lysozyme, the suspension of cells was stirred with a magnetic stirrer. After the addition, the temperature was adjusted to $37^{\circ} \mathrm{C}$. Incubation was carried out bystirring for 12 $\min$ at $37^{\circ} \mathrm{C}$, followed by addition of ethylenediaminetetraacetic acid (EDTA) by slow dilution using $0.1 \mathrm{M}$ dipotassium EDTA (pH 7.0) (1: 10, v/v, EDTA /cell) with prewarmed $\left(37^{\circ} \mathrm{C}\right)$ EDTA, added slowly over $2.5 \mathrm{~min}$ with continuous stirring to avoid lysis. The temperature dropped during this addition, and was adjusted back to $37^{\circ} \mathrm{C}$. Within 8 to $10 \mathrm{~min}$, more than $99 \%$ of the cells became spherical [11]. Protoplasts were harvested by centrifugation at $4^{\circ} \mathrm{C}$ at 5,000 rpm for $10 \mathrm{~min}$ and suspended in SMM buffer (sucrose 0.5M, $\mathrm{MgCl}_{2}$ 0.02M, sodium maleate 0.02M, $\mathrm{pH} 6.5$ ).

\subsection{Protoplast Fusion}

Protoplasts from $P$. ostreatus and E. coli were prepared as described previously. After washing with osmotic stabilizer, protoplasts were mixed and centrifuged (4000 rpm, $10 \mathrm{~min}$ ). The protoplasts were suspended in $1 \mathrm{ml}$ of a pre-warmed $\left(30^{\circ} \mathrm{C}\right)$ solution of $30 \%(\mathrm{w} / \mathrm{v})$ polyethylene glycol (PEG) 6000 in $0.01 \mathrm{M} \mathrm{CaCl} \cdot 2 \mathrm{H}_{2} \mathrm{O}$ and $0.05 \mathrm{M}$ glycine $(\mathrm{pH} 7.5)$ and incubated for $10 \mathrm{~min}$ at $30^{\circ} \mathrm{C}$. The osmotic stabilizer was then added, and the protoplasts were resedimented by centrifugation and resuspended in stabilizer. Protoplasts in stabilizer were plated in $15 \mathrm{ml}$ of regeneration agar at $30^{\circ} \mathrm{C}$. The regeneration agar consisted of solid PDA medium supplemented with osmotic stabilizer was adjusted to $\mathrm{pH}$ 6.0. Subsequently, the plates were incubated at $30^{\circ} \mathrm{C}$ for $3-4$ days.

\subsection{Analytical Method}

Laccase activity was determined as described by NikuPaavola et al. [12]. The protoplasts regeneration ratio was obtained as shown below.

The protoplasts regeneration ratio $(\%)=\frac{C-B}{A-B} \times 100 \%$

Where A is total colony number of the solid PDA (the cells without enzyme-treatment were spread onto the solid PDA);
$\mathrm{B}$ is colony number of the solid PDA (the cells with enzymetreatment were washed twice with distilled water to lyse protoplasts and spread onto the solid PDA) [13]; C is colony number of the regeneration medium plates (protoplasts from different populations were mixed and spread on the regeneration medium plates and were also incubated) [14].

\section{RESULTS AND DISCUSSION}

\subsection{Effect of Different Enzyme Combinations on Protoplasts Formation and Regeneration of $P$. ostreatus}

Considering the composition complexity of the cell walls of $P$. ostreatus, three kinds of hydrolytic enzymes were tested for protoplasts isolation. Comparison of different combinations showed that the enzyme mixture containing $1.5 \%$ cellulase and $1.0 \%$ snailase was more effective than cellulase, snailase, lywallzyme alone, or cellulase mixed with snailase and lywallzyme (Table 1). The results showed that the protoplasts formation and regeneration ratio of $P$. ostreatus were $5.01 \times 108$ and $7.31 \%$ in $1.5 \%$ cellulase and $1.0 \%$ snailase, respectively.

\subsection{Effect of Incubation Time on Protoplast Formation and Regeneration of $P$. ostreatus}

As illustrated in Fig. (1), the optimal incubation period for rapid protoplast formation and regeneration of $P$. ostreatus was 6 days. The incubation time showed a highly significant effect on the protoplast yield. As shown in Fig. (1), on the fifth and sixth day, the protoplast formation was efficient. The effect of enzymolysis is poor when the incubation time is too short or too long. Cell wall is the enzyme substrate. The fungi in different physiological state directly affect the cell wall structure, metabolism and the vitality of fungi. When the incubation time is 5-6 d, hypha growth is enough and easy to take off the wall.

\subsection{The effect of Osmotic Stabilizer on Protoplast Formation and Regeneration of $P$. ostreatus}

The osmotic stabilizer also plays an important role in protoplast isolation. Appropriate concentration of osmoticum can prevent the protoplast from bursting or shrinking. Though there is no uniform standard for the selection of a suitable osmotic stabilizer $[10,15]$, it was demonstrated in this study that mannitol was a good choice for P. ostreatus. The best results were achieved with the $0.6 \mathrm{M}$ mannitol osmotic stabilizer with protoplast formation and regeneration of $P$. ostreatus of $4.13 \times 10^{8}$ and $5.67 \%$, respectively

Table 1. Effect of different enzymes on protoplasts formation and regeneration of $P$. ostreatus.

\begin{tabular}{|c|c|c|}
\hline Enzyme Solution & Protoplasts Formation (10 $\left.{ }^{\mathbf{8}}\right)$ & Regeneration Ratio (\%) \\
\hline \hline $2 \%$ Cellulase & 4.97 & 6.33 \\
\hline $1.5 \%$ Snailase & 4.35 & 6.73 \\
\hline $1.0 \%$ Lywallzyme & 3.59 & 4.91 \\
\hline $1.5 \%$ Cellulase $+1.0 \%$ Snailase & 5.01 & 7.31 \\
\hline
\end{tabular}


(Fig. 2). The rest of the order was $\mathrm{KCl}>\mathrm{MgSO}_{4} \cdot 7 \mathrm{H}_{2} \mathrm{O}$ $>\mathrm{NaCl}$.

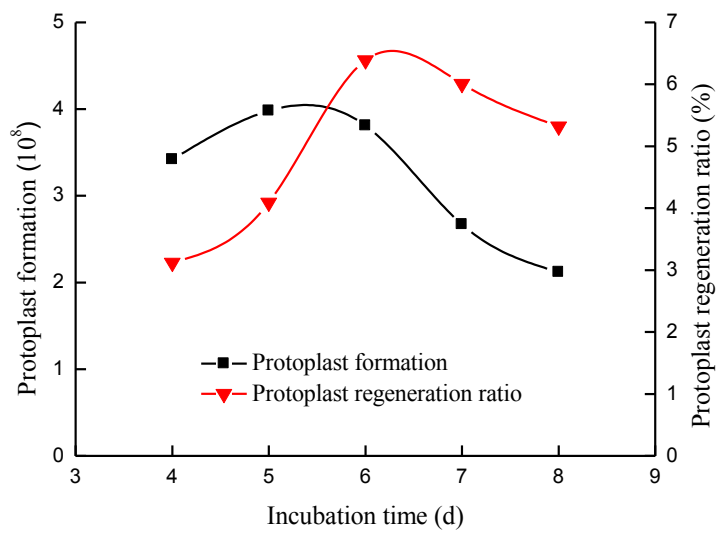

Fig. (1). Effect of incubation time on protoplast formation and regeneration ratio.

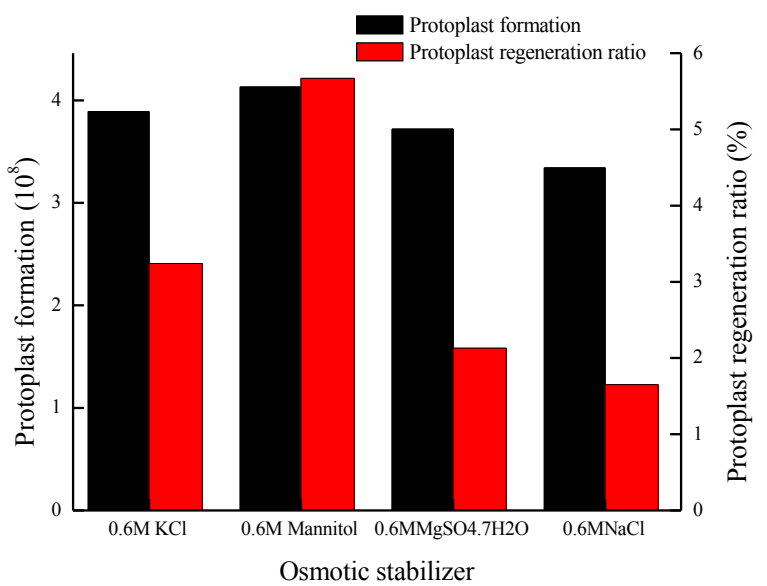

Fig. (2). Effect of osmotic stabilizer on protoplast formation and regeneration ratio.
3.4. Optimization of Protoplasts Formation and Regeneration Conditions

To optimize the protoplasts formation and regeneration conditions, a four-factor, three-level cross design test was conducted. The design and result are shown in Table 2. Based on the results ( $\mathrm{k}$ value) shown in Table $\mathbf{2}$, the best combination for protoplasts formation and regeneration was $1.5 \% \mathrm{C}+1.0 \% \mathrm{~S}, 3.0 \mathrm{~h}, 30^{\circ} \mathrm{C}, 0.6 \mathrm{M}$ mannitol. Based on the value of $r$, the time of enzymolysis played the most important role. The rest of the order was enzyme combination $>$ enzymolysis temperature $>$ osmotic stabilizer.

\subsection{Fusion of Protoplasts}

A total of 6 fusants were selected for further screening. Since the aim of this study was to find a fusant with high laccase productivity, fusants based on the following criteria were screened: first, it must grow very well in selecting medium; second, it must have the highest laccase production. Based on these criteria, fusant $\mathrm{F}$ was selected for the study (Fig. 3). The fusant $\mathrm{F}$ showed comparatively higher laccase activity to that of other fusants, and it had the fastest growth. In the present work, protoplast fusion of $P$. ostreatus and $E$. coli improved the laccase yield by $22 \%$.

\subsection{The Genetical Stability of The Fusant $\mathbf{F}$}

To ascertain whether fusant $\mathrm{F}$ is genetically stable, it was traced for 10 generations to measure the laccase activity of every other generation. All the generations demonstrated similar activity and productivity as the original $\mathrm{F}$, suggesting that this fusant is genetically stable and suitable for industrial production. In addition, fermentation condition was also optimized for this strain (data not shown). The laccase activity reached $190.5 \mathrm{U} / \mathrm{ml}$.

Table 2. Cross design test to optimize protoplasts formation and regeneration of $P$. ostreatus.

\begin{tabular}{|c|c|c|c|c|c|}
\hline $\begin{array}{c}\text { Experimental } \\
\text { No. }\end{array}$ & $\begin{array}{c}\text { Enzyme } \\
\text { Combination }\end{array}$ & $\begin{array}{l}\text { Enzymolysis } \\
\text { Time }\end{array}$ & $\begin{array}{l}\text { Enzymolysis } \\
\text { Temperature }\end{array}$ & $\begin{array}{l}\text { Osmotic } \\
\text { Stabilizer }\end{array}$ & $\begin{array}{l}\text { Protoplasts Formation }(\mathrm{X}) \times \\
\text { Regeneration Ratio }(\mathrm{Y})\left(\mathbf{1 0}^{6}\right)\end{array}$ \\
\hline 1 & $1.5 \% \mathrm{C}$ & $2.5 \mathrm{~h}$ & $28^{\circ} \mathrm{C}$ & $0.6 \mathrm{M} \mathrm{KCl}$ & 8.96 \\
\hline 2 & $1.5 \% \mathrm{C}$ & $3.0 \mathrm{~h}$ & $30^{\circ} \mathrm{C}$ & $0.6 \mathrm{M} \mathrm{MgSO}{ }_{4} \cdot 7 \mathrm{H}_{2} \mathrm{O}$ & 27.33 \\
\hline 3 & $1.5 \% \mathrm{C}$ & $3.5 \mathrm{~h}$ & $32^{\circ} \mathrm{C}$ & 0.6M Mannitol & 11.67 \\
\hline 4 & $1.5 \% \mathrm{C}+1.0 \% \mathrm{~S}+0.5 \% \mathrm{~L}$ & $2.5 \mathrm{~h}$ & $30^{\circ} \mathrm{C}$ & 0.6M Mannitol & 10.12 \\
\hline 5 & $1.5 \% \mathrm{C}+1.0 \% \mathrm{~S}+0.5 \% \mathrm{~L}$ & $3.0 \mathrm{~h}$ & $32^{\circ} \mathrm{C}$ & $0.6 \mathrm{M} \mathrm{KCl}$ & 12.32 \\
\hline 6 & $1.5 \% \mathrm{C}+1.0 \% \mathrm{~S}+0.5 \% \mathrm{~L}$ & $3.5 \mathrm{~h}$ & $28^{\circ} \mathrm{C}$ & $0.6 \mathrm{M} \mathrm{MgSO}{ }_{4} \cdot 7 \mathrm{H}_{2} \mathrm{O}$ & 4.69 \\
\hline 7 & $1.5 \% \mathrm{C}+1.0 \% \mathrm{~S}$ & $2.5 \mathrm{~h}$ & $32^{\circ} \mathrm{C}$ & $0.6 \mathrm{M} \mathrm{MgSO}_{4} \cdot 7 \mathrm{H}_{2} \mathrm{O}$ & 9.65 \\
\hline 8 & $1.5 \% \mathrm{C}+1.0 \% \mathrm{~S}$ & $3.0 \mathrm{~h}$ & $28^{\circ} \mathrm{C}$ & 0.6M Mannitol & 25.09 \\
\hline 9 & $1.5 \% \mathrm{C}+1.0 \% \mathrm{~S}$ & $3.5 \mathrm{~h}$ & $30^{\circ} \mathrm{C}$ & $0.6 \mathrm{M} \mathrm{KCl}$ & 21.23 \\
\hline $\mathrm{k}_{1}$ & 15.987 & 9.577 & 12.913 & 14.170 & \\
\hline $\mathrm{k}_{2}$ & 9.043 & 21.580 & 19.560 & 13.890 & \\
\hline $\mathrm{k}_{3}$ & 18.657 & 12.530 & 11.213 & 15.627 & \\
\hline $\mathrm{r}$ & 9.641 & 12.003 & 8.347 & 1.737 & \\
\hline
\end{tabular}




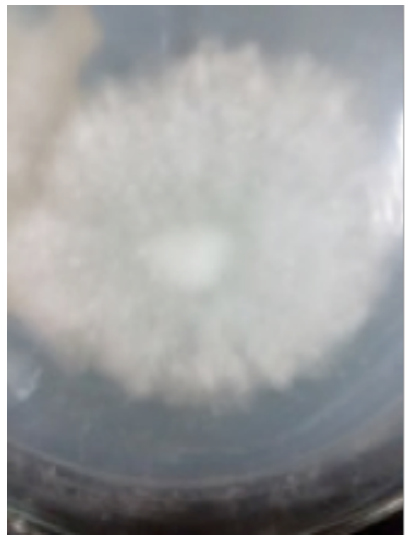

(a)

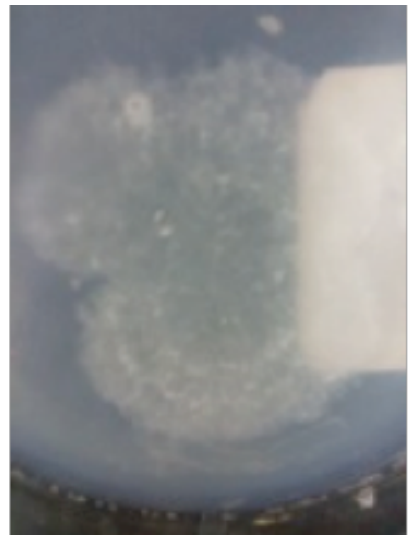

(b)

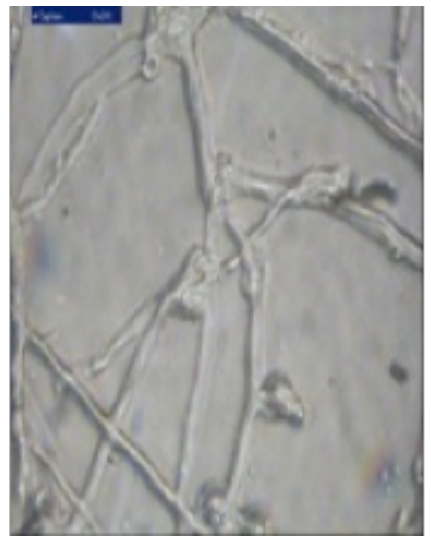

(c)

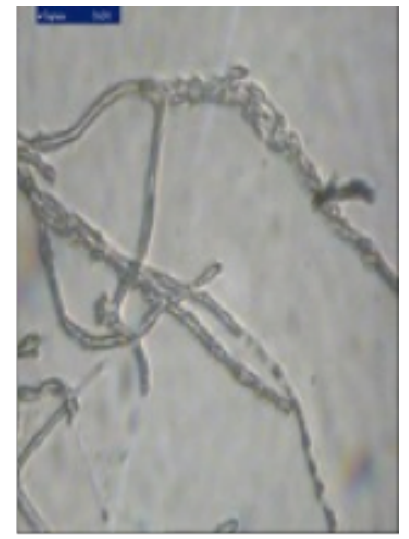

(d)

Fig. (3). The colonies and cell morphology of parental strains and fusant F. (a) The colonies of parental strain P. ostreatus; (b) The colonies of fusant F; (c) Cell morphology of parental strain P. ostreatus; (d) Cell morphology of fusant F.

\section{CONCLUSION}

Using the inter-kingdom protoplast fusion method, a fusant between $P$. ostreatus and $E$. coli was successfully produced. Results of the present work clearly confirmed the highly effective role of protoplast fusion in enhancing laccase production capacity of $P$. ostreatus and its rate of growth suggesting that this fusant is genetically stable. Protoplast fusion of $P$. ostreatus strains resulted in laccase yield increase by $22 \%$ compared to their parent strain, which is considered an excellent result. Thus, it is a very promising strain for industrial application. In conclusion, protoplast fusion proved its efficiency as a tool for constructing a second generation with much better characteristics for efficient and economical field applications.

\section{CONFLICT OF INTEREST}

The authors confirm that this article content has no conflict of interest.

\section{ACKNOWLEDGEMENTS}

This work is supported by the National Natural Science Foundation of China (No.51408290) and the Natural Science Foundation of Liaoning Province, China (No.2014020112).

\section{REFERENCES}

[1] Giardina P, Faraco V, Pezzella C, Piscitelli A, Vanhulle S, Sannia G. Laccases: a never-ending story. Cell Mol Life Sci 2010; 67: 369-85.

[2] Singh G, Kaur K, Puri S, Sharma P. Critical factors affecting laccase-mediated biobleaching of pulp in paper industry. Appl Microbiol Biotechnol 2015; 99: 155-64.

[3] Mohajershojaei K, Khosravi A, Mahmoodi NM. Decolorization of dyes using immobilized laccase enzyme on zinc ferrite nanoparticle from single and binary systems. Fibers Polymers 2014; 15: 2139-45.
[4] Kulshreshtha S, Mathur N, Bhatnagar P. Aerobic treatment of handmade paper industrial effluents by white rot fungi. Bioremed Biodeg 2012; 3: 1-7.

[5] Imada C, Okanishi M, Okami Y. Intergenus protoplast fusion between Streptomyces and Micromonospora with reference to the distribution of parental characteristics in the fusants. J Biosci Bioeng 1999; 88: 143-7.

[6] Verma V, Qazi GN, Parshad R. Intergeneric protoplast fusion between Gluconobacter oxydans and Corynebacterium species. J Biotechnol 1992; 26: 327-30.

[7] Chen XY, Wei PL, Fan LM, Yang D, Zhu XC, Shen WH, Xu ZN, C PL. Generation of high-yield rapamycin-producing strains through protoplasts-related techniques. Appl Microbiol Biotechnol 2009; 83: 507-12.

[8] Wei WL, Wu KL, Qin Y, Xie Z, Zhu XS. Intergeneric protoplast fusion between Kluyveromyces and Saccharomyces cerevisiae - to produce sorbitol from Jerusalem artichokes. Biotechnol Lett 2001; 23: 799-803.

[9] Li M, Yi P, Liu Q, Pan Y, Qian GR. Biodegradation of benzoate by protoplast fusant via intergeneric protoplast fusion between Pseudomonas putida and Bacillus subtili. Int Biodeter Biodegr 2013; 85: 577-82.

[10] Gold MH, Cheng TM, Alic M. Formation, fusion, and regeneration of protoplasts from wild-type and auxotrophic strains of the white rot basidiomycete Phaonerochaete chrvsosporium. Appl Environ Microbiol 1983; 46: 260-3.

[11] Weiss RL. Protoplast formation in Escherichia coli. J Bacteriol 1976; 128: 668-70.

[12] Niku-Paavola ML, Raaska L, Itävaara M. Detection of white rot fungi by a non-toxic stain. Mycol Res 1990; 94: 27-31.

[13] John RP, Gangadharan D, Madhavan NK. Genome shuffling of Lactobacillus delbrueckii mutant and Bacillus amyloliquefaciens through protoplasmic fusion for 1-lactic acid production from starchy wastes. Bioresource Technol 2008; 99: 8008-15.

[14] Zheng HJ, Gong JX, Chen T, Chen X, Zhao XM. Strain improvement of Sporolactobacillus inulinus ATCC 15538 for acid tolerance and production of D-lactic acid by genome shuffling. Appl Microbiol Biotechnol 2010; 85: 1541-49.

[15] Sivakumar U, Kalaichelvan G, Ramasamy K. Protoplast fusion in Streptomyces $\mathrm{sp}$. for increased production of laccase and associated ligninolytic enzymes. World J Microb Biot 2004; 20: 563-68. 